\title{
Spatial parameters for transportation: A multi-modal approach for modelling the urban spatial structure using deep learning and remote sensing
}

\author{
Dorothee Stiller \\ German Aerospace Center \\ dorothee.stiller@dlr.de \\ Pablo d'Angelo \\ German Aerospace Center \\ pablo.angelo@dlr.de \\ Hannes Taubenböck \\ German Aerospace Center \\ \& University of Wuerzburg \\ hannes.taubenboeck@dlr.de
}

\author{
Michael Wurm \\ German Aerospace Center \\ michael.wurm@dlr.de \\ Karsten Stebner \\ German Aerospace Center \\ karsten.stebner@dlr.de
}

\author{
Thomas Stark \\ Technical University of \\ Munich \\ t.stark@tum.de \\ Stefan Dech \\ German Aerospace Center \\ \& University of Wuerzburg \\ stefan.dech@dlr.de
}

\begin{abstract}
A significant increase in global urban population affects the efficiency of urban transportation systems. Remarkable urban growth rates are observed in developing or newly industrialized countries where researchers, planners, and authorities face scarcity of relevant official data or geo-data. In this study, we explore remote sensing and open geo-data as alternative sources to generate missing data for transportation models in urban planning and research. We propose a multi-modal approach capable of assessing three essential parameters of the urban spatial structure: buildings, land use, and intra-urban population distribution. Therefore, we first create a very high-resolution (VHR) 3D city model for estimating the building floors. Second, we add detailed land-use information retrieved from OpenStreetMap (OSM). Third, we test and evaluate five experiments to estimate population at a single building level. In our experimental set-up for the mega-city of Santiago de Chile, we find that the multi-modal approach allows generating missing data for transportation independently from official data for any area across the globe. Beyond that, we find the high-level 3D city model is the most accurate for determining population on small scales, and thus evaluate that the integration of land use is an inevitable step to obtain fine-scale intra-urban population distribution.
\end{abstract}

Keywords: Urban spatial structure, built environment, 3D city model, land-use model, intra-urban population, data fusion

\section{Article history:}

Received: July 22, 2020

Received in revised form:

December 16, 2020

Accepted: March 18, 2021

Available online: July 7, 2021

\section{Introduction}

Cities are hotspots of transportation. This phenomenon gets intensified by the steady growth and den-

Copyright 2021 Dorothee Stiller, Michael Wurm, Thomas Stark, Pablo d'Angelo, Karsten Stebner, Stefan Dech \& Hannes Taubenböck

http://dx.doi.org/10.5198/jtlu.2021.1855

ISSN: 1938-7849 | Licensed under the Creative Commons Attribution - Noncommercial License 4.0

The Journal of Transport and Land Use is the official journal of the World Society for Transport and Land Use (WSTLUR) and is published and sponsored by the University of Minnesota Center for Transportation Studies. 
sification of urban populations (United Nations, 2019). On the one hand, the spatial proximity within cities promotes innovation, economic wealth, education, and thereby attracts more and more people to move into urban agglomerations (e.g., Glaeser, 2011). On the other hand, a spatial concentration has also negative implications, e.g., shortage of space, increase in pollution, noise emission, and congestion. Transportation related pollution and noise are particularly problematic in dense urban environments, being a public health concern for the local population (Choi \& Zhang, 2017; Okokon et al., 2015). Additionally, inadequate urban transportation has also economic and environmental impacts (Rodrigue, Comtois, \& Slack, 2016).

The urban spatial structure plays an important role in urban transportation research and describes the morphological dimensions, but also the functional features of a city (Krehl, Siedentop, Taubenböck, $\&$ Wurm, 2016). This includes the distribution of transportation networks, flows of goods and services, (un)employment, population, and land use among others (Farber \& Li, 2013; Parr, 2013). The urban spatial structure was found to be associated with, e.g., mode choice (Tracy, Su, Sadek, \& Wang, 2011), active travel (Cheng et al., 2019), level of human activity (Chen, Hui, Wu, Lang, \& Li, 2019), commuting patterns (Sohn, 2005), travel time, private transport energy consumption (Liddle, 2013), and vehicle miles traveled (VMT) (Ihlanfeldt, 2020) including $\mathrm{CO}_{2}$ emissions (Lee \& Lee, 2020). Accordingly, active planning of characteristics of the urban spatial structure is understood as an effective tool for transportation planning, often described as smart growth (Jin, 2019; Tracy et al., 2011). Furthermore, characteristics of the urban spatial structure including land use as well as population and their distribution are crucial to predict travel behavior and estimate travel demand (Zhang, Liu, Tang, Cheng, \& Wang, 2019). This information serves as base data for models addressing transportation forecasting, e.g., aiming at purposes for trip generation and origin/destination $(\mathrm{O} / \mathrm{D})$ estimations (Machado \& Quintanilha, 2019). Buildings, for example, serve as the minimal spatial units where trips originate and end (Sevtsuk \& Mekonnen, 2012), and are the basis to further define land use and population (Hecht, Kunze, \& Hahmann, 2013). Therefore, sufficient knowledge about the urban spatial structure is necessary to create adequate countermeasures, and reduce negative concomitants of transportation while satisfying the need for mobility for everyone. However, we experience a lack of relevant base data for many populated places, e.g., for estimating transportation demands (Levashev, 2017). Although the quality and quantity of open geo-data continues to increase, e.g., from OSM (Barrington-Leigh \& Millard-Ball, 2017; Tian, Zhou, \& Fu, 2019), many regions are still underrepresented. Especially in highly dynamic cities of the Global South these necessary data are often outdated, incomplete, not reliable or generally inexistent (Cervero, 2013; Walker, Srinivasan, \& Bolduc, 2010). In addition, traditional methods like surveys and traffic counting to collect data for $\mathrm{O} / \mathrm{D}$ estimations can often not be implemented in developing countries due to a lack of financial resources and skilled personnel, complicated by high urban crime rates (Machado \& Quintanilha, 2019). These circumstances lead to the fact that suitable transportation models are underrepresented in developing countries (Wang, Mishra, Ye, Li, \& Wu, 2017). Moreover, data at the administrative level are often main data sources for transportation forecasting. However, these aggregated spatial units cannot be considered as ideal and entities with a higher level of detail are favorable, especially in dense urban environments (Nordenholz, Metzler, \& Winkler, 2019). A high spatial resolution of reliable base data is also advantageous for agent-based models, e.g., for studying the effect of transportation for the local population in regard to traffic-related noise (Kaddoura, Kröger, \& Nagel, 2016) and emissions (Linton, Grant-Muller, \& Gale, 2015). Where relevant data are not available, there is a need for alternative sources.

Remote Sensing might serve as such an alternative, possibly able to provide missing data for transportation (Machado \& Quintanilha, 2019). Remote sensing 1) allows large area coverage beyond administrative boundaries, 2) provides an objective framework independently from official sources, 3) helps to gather up-to-date information, and 4) is time and cost efficient. Although remote sensing usage 
requires specialist knowledge (de Sherbinin et al., 2002; Young et al., 2017) and assumes availability of the respective data, it was used in various studies in the context of transportation (Bowen, Vlasek, \& Webb, 2004; Guindon \& Zhang, 2007; Kopsiaftis \& Karantzalos, 2015; Machado \& Quintanilha, 2019; Palubinskas, Kurz, \& Reinartz, 2010; Salvo, Caruso, Scordo,Guido, \& Vitale, 2017; Zhang \& Guindon, 2006; Zhang, Guindon, \& Sun, 2010). For example, Aljoufie, Zuidgeest, Brussel, and van Maarseveen (2013) analyzed the spatio-temporal relationship of urban growth and transportation. Dincer, Akdemir, Ulvi, and Duzkaya (2019) revealed how infrastructure projects have led to an increase in built-up areas and population using Landsat data. In general, remote sensing data allow to capture various aspects of the urban spatial structure: To monitor the spreading of settlements, it is possible to derive their extent, which describes the 2D horizontal spreading (Angel, Parent, Civco, Blei, \& Potere, 2011; Taubenböck et al., 2019). With height information retrieved from stereo or tri-stereo satellite data, it is possible to create a digital surface model (DSM) or a normalized DSM (nDSM), which makes it possible to furthermore derive the vertical spreading of cities and urban densities as proxies (Wurm, Taubenböck, Schardt, Esch, \& Dech, 2011; Wurm, d' Angelo, Reinartz, \& Taubenböck, 2014). Additionally, the combination of remote sensing and Google Street View enables to derive building floors, which allows in-depth analyses of the urban spatial structure (María, Hube, Rivera, Yepes-Estrada, \& Valcárcel, 2016; Taubenböck, Kraff, \& Wurm, 2018).

The goal of this study is to demonstrate the feasibility of remote sensing based data and derived geoinformation as proxies to support transportation-related studies, especially for areas with data scarcity. To do so, this study focuses on three factors which first significantly contribute to the characteristics of the urban spatial structure, and further can be accessed using remote sensing and open geo-data: 1) buildings, 2) land use, and 3) population (discussed in detail in Section 2). These three key parameters of the urban spatial structure are derived at a very high spatial resolution for the exemplary mega-city of Santiago de Chile to address the following aspects:

1) Where are buildings located and how can these be characterized according to their area, height, and number of floors?

2) Which type of land use can be assigned to these buildings, and consequently, how is land use distributed throughout the city?

3) How many people can be attributed to each building, and therefore, how about the intra-urban population distribution? What kind of data is needed to achieve reasonable population num bers supporting transportation models?

Hence, we create a multi-modal 3D functional model capable of capturing these important features of the urban spatial structure with four levels of details. In a first step, we create the 3D buildings (Level-1). Therefore, we combine cutting edge deep learning methods for semantic segmentation of area-wide orthophotos for the derivation of building footprints with height information from an nDSM. In a second step, we use Google Street View to obtain the number of floors for a sample of buildings for training a regression model to derive city-wide building floors (Level-2). Third, we use OSM land-use polygons and points of interest (POIs) to add detailed land-use information (Level-3). Fourth, we estimate population at single building level to determine intra-urban variations in population (Level-4). For this, we carry out five experiments using different levels of detail, which are intended to show which level of detail is decisive for a valid population distribution. The data used in this study are available for many parts of the world, but unfortunately not globally. Therefore, these experiments allow us to assess the possibilities and limitations for other data scenarios as well. Section 2 introduces the three key parameters in detail. Section 3 describes the study region and the data used. Section 4 outlines the methods to obtain the functional 3D city model encompassing the three key parameters. Section 5 presents the results including the validation of the functional 3D model with its four levels of detail. Section 6 discusses the findings. 


\section{Background}

This section focuses on the three parameters of the urban spatial structure addressed in this study: buildings, land use, and population. For each parameter, it highlights its relevance within the context of urban transportation, and reviews methods of their determination through remote sensing.

\subsection{Buildings}

Main features of the urban spatial structure are buildings. They can be considered as the basic physical component of a city's spatial structure, and are needed as a baseline for any further semantic determination, e.g., land use and population (Hecht et al., 2013). It is possible to derive the built density or compactness metrics from building data (2D and 3D), which was found to be an essential characteristic for matters of the urban transportation system (Chen et al., 2019; Liddle, 2013; Resch, Bohne, Kvamsdal, \& Lohne, 2016). Despite their importance for urban planning and research, building data are scarce for many regions throughout the world. Although OSM provides building footprints, there is only little known about their worldwide completeness. However, for example, their completeness for the region Lombardy in Northern Italy has been identified to be at 57\% (Brovelli \& Zamboni, 2018). For Munich, Germany, Fan, Zipf, Fu, and Neis (2014) found a high degree of completeness, however with less information on the building attributes, e.g., height or number of floors. It can be assumed that completeness and attribute data are worse in other regions, e.g., in non-industrialized countries. Remote sensing imagery can serve as an alternative source to gather missing building data. Although it has been a task within the remote sensing community for some time, building extraction remains a challenging task (Bittner, Cui, \& Reinartz, 2017; Ghanea, Moallem, \& Momeni, 2016). Recently, novel approaches using deep learning have outperformed traditional methods (Ma et al., 2019; Zhu et al., 2017). They have been found to be very precise in building extraction tasks (Hui, Du, Ye, Qin, \& Sui, 2019) using semantic segmentation and transfer learning (Wurm, Stark, Zhu, Weigand, \& Taubenböck, 2019b). With these 2D footprints it is possible to further add height information and create 3D buildings by using an nDSM derived from satellite data (Wurm et al., 2021). A DSM contains the height of all objects on the earth's surface, both natural and artificial features are depicted. An nDSM obtains only the heights of objects in relation to the ground surface, i.e., the height of the buildings. The 3D buildings can be used as the baseline to determine further important factors of the urban spatial structure: land use and population (e.g., Wurm et al., 2011).

\section{$2.2 \quad$ Land use}

Each type of land use has its specific impact on mobility requirements and can serve as a generator or attractor of movements (Nuhn \& Hesse, 2006). Diverse land use has been associated with shorter trips (Srinivasan, Provost, \& Steiner, 2013), a reduction in driving emission through VMT cutback (Choi \& Zhang, 2017), an increase in public transportation usage (Stevenson et al., 2016), and a higher probability using non-motorized modes (Duncan et al., 2010; Faghih-Imani et al., 2014). Commuting mode choice and patterns were also found to be related to land use ( $\mathrm{Hu}, \mathrm{Xu}$, Shen, Shi, \& Chen, 2018; Jin, 2019; Sun, Ermagun, \& Dan, 2017), although a study suggests that the effect of land use on mode choice differs between trips and tours (van Acker \& Witlox, 2010). Additionally, the intra-urban distribution of a certain land-use type within a city can support or hinder private auto ownership. Cao, Naess, and Wolday (2019) found that relocating residential areas outward of the city increases auto ownership, and relocating residential areas inward of the urban area decreases auto ownership. For retrieving relevant land use, there is an increasing amount of studies using volunteered geographic information 
(VGI) data, especially from OSM (OpenStreetMap contributors, 2017). The advantage of using OSM land-use data is that they provide a free and highly detailed database, enabling a more detailed land-use determination, which could not be assessed by using solely remote sensing data (Fonte et al., 2017; Schultz, Voss, Auer, Carter, \& Zipf, 2017). Land use does also play a key role for population estimation tasks (Biljecki, Ohori, Ledoux, Peters, \& Stoter, 2016).

\subsection{Population}

Population is often used as a key variable for travel demand estimation (Choupani \& Mamdoohi, 2016) and accessibility analyses (Sarlas, Páez, \& Axhausen, 2020). High population density positively affects shared bicycle flows (Faghih-Imani, Eluru, El-Geneidy, Rabbat, \& Haq, 2014), and decreases the likelihood of owning more than one car (Soltani \& Somenahalli, 2005), thereby promotes sustainability within the transportation sector. Furthermore, Zhang and Guindon (2006) emphasized that intra-urban population variation is a decisive factor for urban transportation systems. Srinivasan et al. (2013) found that a high density of residential population and diverse land-use results in shorter trips, emphasizing that both factors are interwoven. Approaches to derive intra-urban population patterns can be separated into top-down and bottom-up, by distributing the total urban population number to smaller entities (e.g., transportation analysis zones (TAZs), administrative areas, etc.) and by scaling-up population from parts of the city to the whole city, respectively (Stevens , Gaughan, Linard, \& Tatem, 2015; Taubenböck, Roth, \& Dech, 2008; Wu, Qui, \& Wang, 2005; Wurm et al., 2009). The advantage of top-down approaches is that no small-scale and detailed population data are necessary, but only the total population number of a city, thereby increasing the transferability of the approach.

\section{$3 \quad$ Study area and data}

\subsection{Santiago de Chile}

Our study area comprises the majority of the urban core called Gran Santiago with a population of 4.9 million (Table 1, Figure 1). We choose Santiago de Chile as our study region, as relevant data were available for testing and validating the proposed approach (Section 3.2-3.6). Furthermore, the urban area of Santiago has experienced a remarkable expansion during the past decades and is expected to grow even further (Puertas, Henríquez, \& Meza, 2014), thereby being a great example of a dynamic city. Santiago has a relatively low motorization rate compared to its economic development. However, the city must deal with significant air pollution, especially with respirable particulates and nitrogen oxides, whereby transportation is the source for $56 \%$ and $87 \%$ of the emissions, respectively (Zegras, 2010). To counteract, the authorities have introduced a permanent restriction since 1986, which bans vehicles having no catalytic converter according to license plate numbers during high-pollution rates (Grange \& Troncoso, 2011). These regulations have been extended subsequently, however, car use was only decreased by introducing a ban for all catalytic converters in the morning on days (Grange \& Troncoso, 2011). 
Table 1. Overview of our study area within Gran Santiago, which is restricted by the data extent of the building footprints (see Section 3.2)

\begin{tabular}{ll}
\hline Area $\left(\mathrm{km}^{2}\right)$ & 591 \\
Population & $4,897,593$ \\
Population density $($ per km²) & 8,282 \\
\hline
\end{tabular}

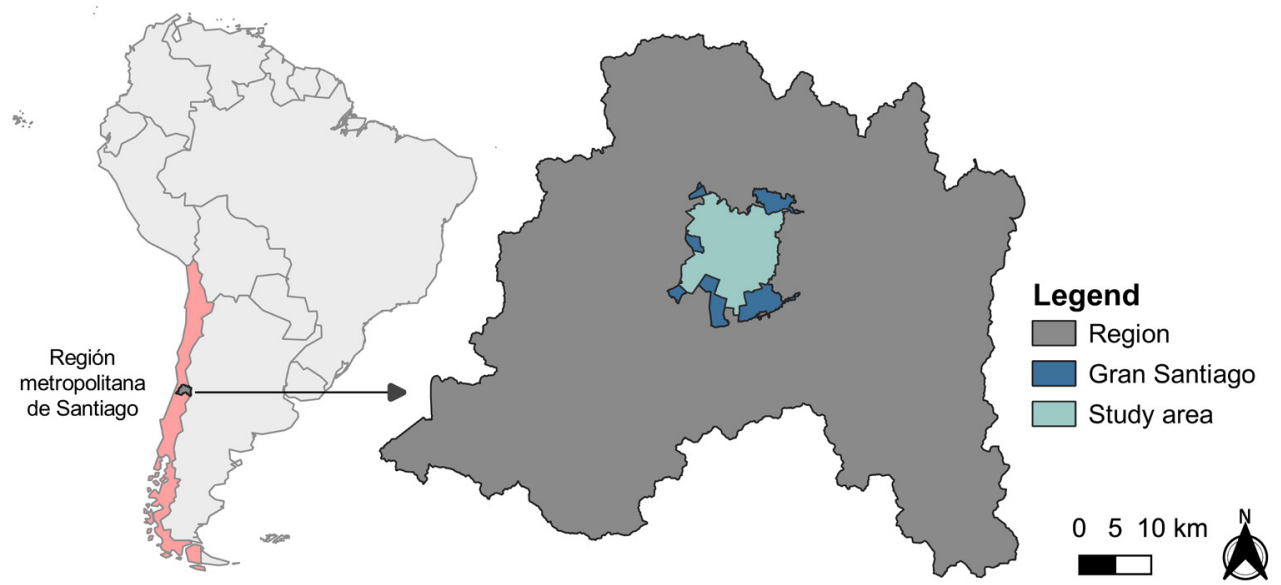

Figure 1. Location of Chile and the region Metropolitana (left), and the region Metropolitana with Gran Santiago and the administrative unit of Gran Santiago with the study area (right)

\subsection{VHR building footprint data}

For Santiago de Chile, freely available building footprint data are scarce, e.g., we observed a poor coverage of OSM building data (Stiller, Stark, Wurm, Dech, Taubenboöck, 2019b). Therefore, we extracted buildings for entire Gran Santiago at a very high spatial resolution using a deep learning approach. For details on the methods we refer to our prior study (Stiller et al., 2019b). In brief, as input data, we used an aerial orthophoto mosaic from 2014 (Figure 2a) with a geometric resolution of $0.35 \mathrm{~m}$ (Infraestructura de Datos Geoespeciales (IDE) Chile, 2019). To extract the buildings within our study area, we used the neural network MASK R-CNN, which has already been pre-trained on satellite imagery during a mapping challenge (Humanity \& Inclusion, 2019). We labelled buildings for training data to fine-tune the deep learning model and to improve the performance (Wurm et al., 2019b). With the fine-tuned model we classified 336,598 buildings for entire Gran Santiago at an overall accuracy of 92\%. For this study, we reused the extracted buildings as building footprints (Figure $2 \mathrm{~b}$ ) and modified these as presented in Section 4.1.

\subsection{DSM and nDSM}

To add height information to the existing $2 \mathrm{D}$ building footprints, and thereby to obtain $3 \mathrm{D}$ objects, e.g., stereo or tri-stereo data can be used. When using stereo imagery, ground and roads are often occluded in densely built-up areas. Tri-stereo imagery is acquired from three perspectives, which reduces these unseen areas and the increased redundancy leads to improved height accuracy. Usually, sub-meter VHR tri-stereo imagery is used to obtain digital elevation models in dense urban regions, however due to the large size of the study area we used panchromatic tri-stereo images from 2014 with a geometric resolution of $2 \mathrm{~m}$ acquired by the SPOT-7 satellite covering an area of about $1,300 \mathrm{~km}^{2}$ over Gran Santiago (Figure 2c). From these, we created a DSM and an nDSM (see Section 4.1). 
To validate the city-wide nDSM from SPOT-7, we used DSM data with a pixel spacing of $0.12 \mathrm{~m}$ derived from VHR DSM of DLR MACS (Lehmann et al., 2011) processed by an algorithm for VHR input data (Piltz, Bayer, \& Poznanska, 2016). The airborne VHR data cover a strip in north-eastern Santiago with a total area of about $17.6 \mathrm{~km}^{2}$ (Figure $2 \mathrm{~d}$ ).

\subsection{Building floors from Google Street View data}

The number of floors per building is an important factor of the urban spatial structure, and serves as an input variable for the population estimation procedure within this study (see Section 4.4). To derive the number of floors per building, we conducted a regression analysis that estimates the floors in dependence on the building height (e.g., Wurm et al., 2019a). Therefore, a sample was created containing 100 buildings from the original building footprint dataset. For this sample, we manually inspected Google Street View imagery to retrieve the number of floors for each building.

\subsection{OSM data: land-use polygons and POls}

The OSM initiative provides free geospatial data to anyone (OpenStreetMap contributors, 2017). We include OSM data for deriving land-use information based at single building level. For that, we used two out of the various datasets that are provided by OSM: land-use polygons and POIs (Figures 2e and 2f). The land-use polygons contain 17 land-use labels for our study area, e.g., residential, commercial, military, park, and industrial. The POIs comprise a total of 114 highly diverse labels, e.g., café, hotel, doctors, shops, school, etc.

For eliminating some misclassifications within the building dataset we used additional OSM data: OSM roads and the OSM water line dataset (procedure described in Section 4.1).

\subsection{Census data}

We used census data from 2017 (Instituto Nacional de Estadísticas (INE) Chile, 2017) containing population numbers on two different spatial scales, i.e., at the administrative levels of manzanas (building blocks) and districts (Table 2). The data were used 1 ) to sum up the small entity population numbers to gather the total population for our study area, and 2) to validate the performance of our approach for estimating the population at building level (Section 4.5).
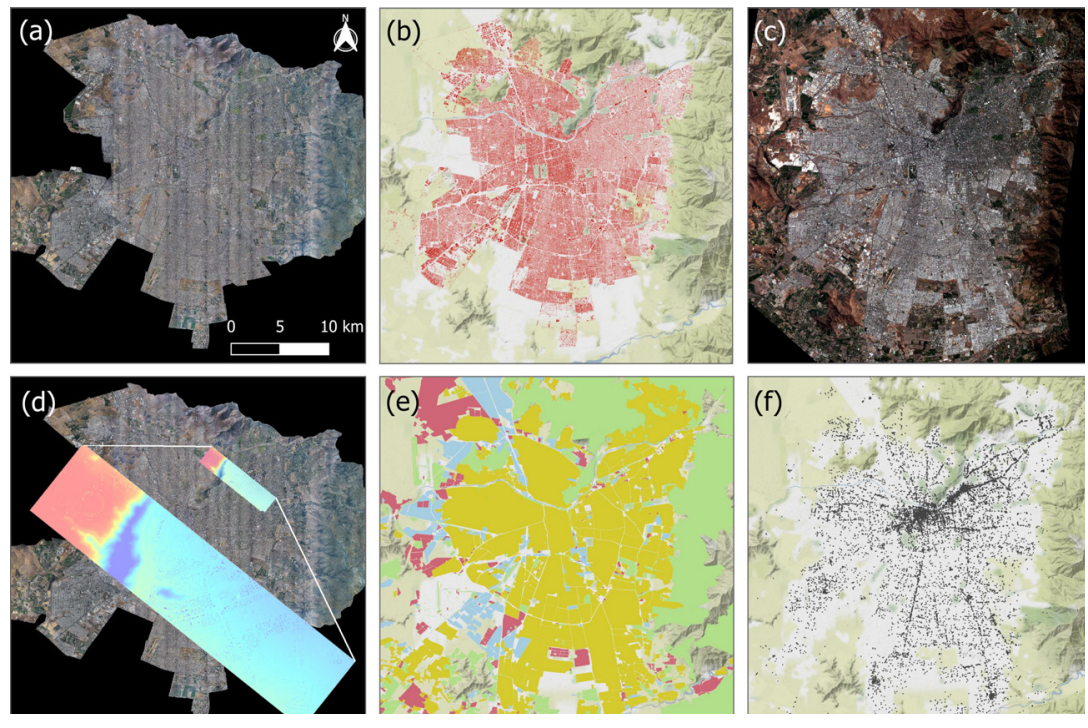

Figure 2. Extent of Gran Santiago aerial imagery that was used to extract the VHR buildings (a), initial building footprint data (b), nadir-multispectral SPOT-7 data (c), location of VHR airborne DSM data (d), OSM land-use polygons (e), and OSM POIs (f) 
Table 2. Characteristics of the 2017 census data from INE

\begin{tabular}{lcc}
\hline & Manzanas & Districts \\
\hline total number of entities & 34,507 & 297 \\
mean size $\left(\mathrm{m}^{2}\right)$ & $14,666 \mathrm{~m}^{2}(\approx 120 \times 120 \mathrm{~m})$ & $2,524,978 \mathrm{~m}^{2}(\approx 1,600 \times 1,600 \mathrm{~m})$ \\
range of size $(\min -\max )\left(\mathrm{m}^{2}\right)$ & $227-4,225,893$ & $376,571-39,845,877$ \\
mean population & 148 & 16,458 \\
\hline
\end{tabular}

\section{$4 \quad$ Methodology: creating the VHR functional 3D Model}

The aim of this study is to create a VHR functional 3D Model with four levels of detail containing decisive parameters for urban transportation systems with regard to the urban spatial structure (Figure 3):

- Level-1: 3D buildings with building heights

- Level-2: 3D buildings with estimated number of floors

- Level-3: 3D buildings with detailed land-use information derived from OSM data

- Level-4: 3D buildings containing estimated population count at the single building level

In the following sections of this chapter, we present the methodology for creating this functional 3D city model.

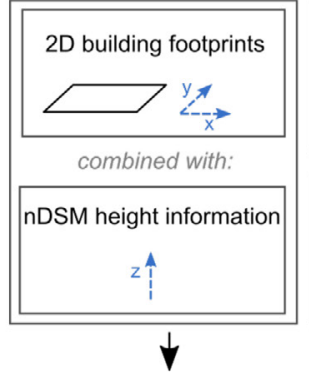

3D buildings

mean height

per building
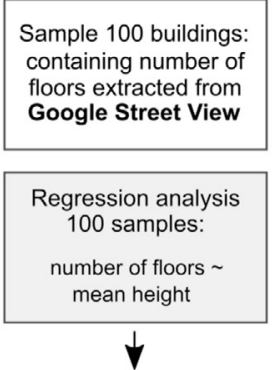

Number of floors

for whole city

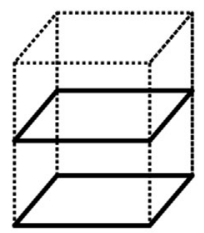

LEVEL-2
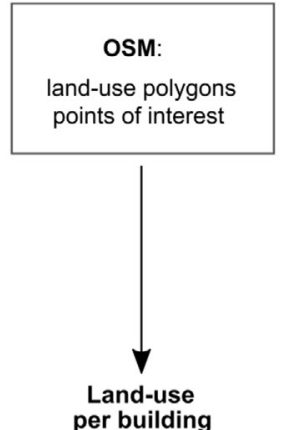

per building

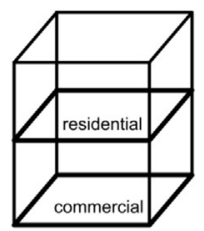

LEVEL-3

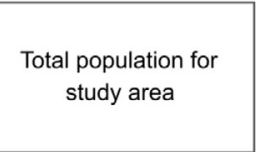

Population distribution:

evaluate the

five experiments
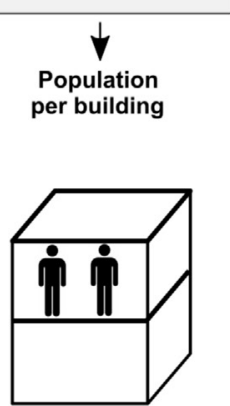

LEVEL-4

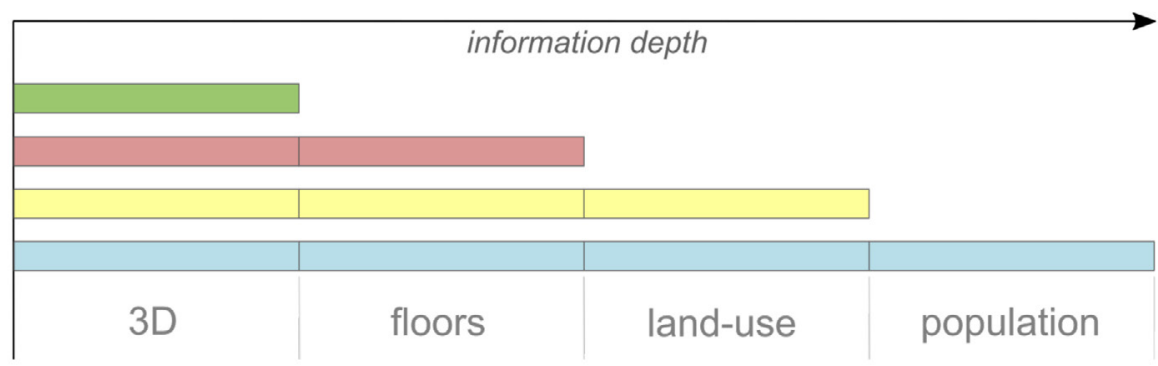

Figure 3. Increase the semantic level of the 3D functional model based on our multi-modal approach: overview of data and methods used for achieving different levels of information depth 


\subsection{Data fusion: 2D building footprints and height information (Level-1)}

The building footprints described in Section 3.2 were reused and optimized regarding several criteria: First, the outline borders were smoothed by applying morphological opening and closing by the extent of 1 pixel. Second, misclassifications were automatically removed within larger streets and within the course of rivers based on spatial intersection by using OSM's roads dataset with the class highway and water line. Third, other minor misclassifications were automatically eliminated by using a size threshold of $2.5 \mathrm{~m}^{2}$. All potential buildings below this threshold were removed, as they were falsely classified as buildings, as they exhibit a similar rectangular shape.

From the SPOT-7 data, a DSM was created after a fully automatic processing system for optical satellite imagery (d'Angelo \& Reinartz, 2011; Krauß, 2014). The SPOT-7 data were co-registered to the location of the orthophoto mosaic, which increases the location accordance of multi-sensor data. To generate an nDSM containing only above-ground information we used the approach proposed by Perko, Raggam, Gutjahr, and Schardt (2015).

The nDSM retrieved from SPOT-7 data was used and combined with the building footprints by using the mean height due to large height differences in the spatial resolution of the two data sources (Wurm et al., 2014). With this, the mean building height was determined for every single building entity for entire Santiago de Chile.

\subsection{Determination of building floors with Google Street View imagery (Level-2)}

To increase the semantic level of the 3D model, the number of floors for every building of Gran Santiago was derived using sampled Google Street View data for 100 buildings. We assume a linear relationship of the mean building height and building floors. Thus, a linear regression analysis was conducted to determine the number of floors per building for our study area. The regression analysis was based on the sample of 100 buildings. The mean building height was used as the explanatory variable and the number of floors as the dependent variable. From the sample of 100 buildings, six outliers were removed during the procedure to build the final model.

\subsection{Extraction of land use from OSM (Level-3)}

To retrieve land use at building level, we included OSM data in our analysis and determined land-use categories in three subsequent steps: sub-categorization, combination, and simplification (Figure 4).

Firstly, we defined relevant land-use categories. Therefore, we used OSM land-use polygons to determine three sub-categories: residential, commercial, and industrial. Furthermore, we used OSM POIs to obtain a finer level of detail (Estima \& Painho, 2015). The POIs comprise a total of 114 label categories. We grouped these diverse point data into the following six sub-categories: commercial, education, accommodation, communal, cultural, and health. Secondly, we combined the two groups of sub-categories to create twelve final land-use classes. We observed that no land-use class was assigned to some buildings, as these were neither covered by the land-use polygon data nor by the POIs. Thirdly, for estimating the population (see next section), we simplified the land-use categories considered either as populated or non-populated. 


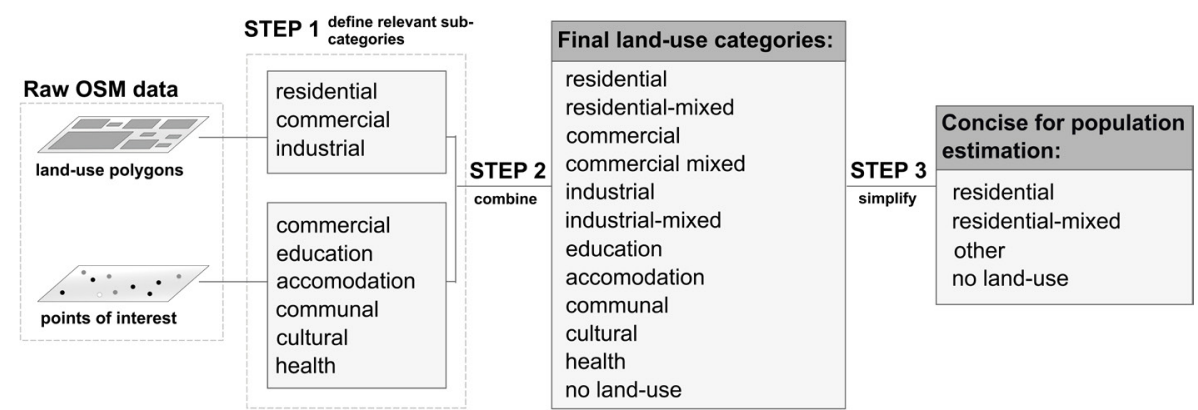

Figure 4. Working scheme on OSM-based land-use categorization within three steps: sub-categorization, combination, and simplification

\subsection{Estimation of population at single building level (Level-4)}

In general, after Wu et al. (2005) methodologies for population estimation can be categorized into 1) areal interpolation methods, also known as disaggregation, and 2) statistical modelling methods. In this study, we used the first method, which supports the transferability of the approach by requiring only one total population count for the proposed study region. We conducted five experiments by subsequently increasing the level of detail by using only one overall population number for the whole area of investigation (Table 3, Figure 5):

- experiment 1 relies on using the area of the building footprints. In former studies, the area of buildings was found to reasonably agree with population numbers (Wu et al., 2008).

- experiment 2 includes the 3D height information. Therefore, population is a function of area and height.

- experiment 3 aims to use the estimated and rounded floor number. From the height $\mathrm{H}(\mathrm{m})$, we estimated a whole number $S$ for assumed floors based on the findings from the regression analysis. For that, we assume:

$$
\begin{aligned}
& \text { for } 0<H<1: \quad S=1 ; \\
& \text { for } 1<H<2: \quad S=2 ; \\
& \ldots . \\
& \text { for } i<\mathrm{H}<j: \quad S=j ; \\
& i: \text { original height }(m) \text { as decimal number } \\
& j: i_{\text {rounded }} \text { (rounded to the higher whole number) }
\end{aligned}
$$

- for experiment $\mathbf{4}$ and $\mathbf{5}$ we used the simplified land-use classes and their relevance as dwelling units, while experiment 4 uses $\mathrm{H}$ and experiment 5 uses $\mathrm{S}$. A building of class "residential" is considered as fully populated, meaning that every floor is considered as a dwelling unit. The class "residential-mixed" is assumed to have one floor not populated (e.g., a shop at the ground floor) (Biljecki et al., 2016). The land-use classes "other" and no land use" are considered as not being populated, e.g., industrial, commercial, etc.

With these five experiments, we systematically tested how the approaches perform in estimating population at single building level using 1) only remote sensing (experiment 1 and 2) and 2) remote sensing in combination with other geo-data (experiment 3, 4 and 5). Therefore, they serve as an indicator for the accuracy of the population estimation that can be expected when using the respective data with different levels of detail, also relevant for data availability and computation power and time. 
Table 3. Overview of five experiments and data used for the population estimation at single building level

\begin{tabular}{|c|c|c|}
\hline & description & required data \\
\hline Experiment $1^{\text {a) }}$ & 2D, Area of building footprints & VHR aerial imagery \\
\hline Experiment $2^{\text {a) }}$ & 3D buildings (area $\times$ height $)$ & $\begin{array}{l}\text { VHR aerial imagery } \\
\text { + stereo-data }\end{array}$ \\
\hline Experiment $3^{\mathrm{b})}$ & Building floors (area $\times$ estimated floor) & $\begin{array}{l}\text { VHR aerial imagery } \\
\text { + stereo-data } \\
\text { + Google Street View }\end{array}$ \\
\hline Experiment $4^{\mathrm{b})}$ & $3 \mathrm{D}+$ land use & $\begin{array}{l}\text { VHR aerial imagery } \\
+ \text { stereo-data } \\
+ \text { OSM }\end{array}$ \\
\hline Experiment $5^{\mathrm{b})}$ & Building floors + land use & $\begin{array}{l}\text { VHR aerial imagery } \\
+ \text { stereo-data } \\
+ \text { Google Street View } \\
+ \text { OSM }\end{array}$ \\
\hline
\end{tabular}

Note: a) experiment conducted using only remote sensing data; b) experiment conducted using remote sensing in combination with other geo-data
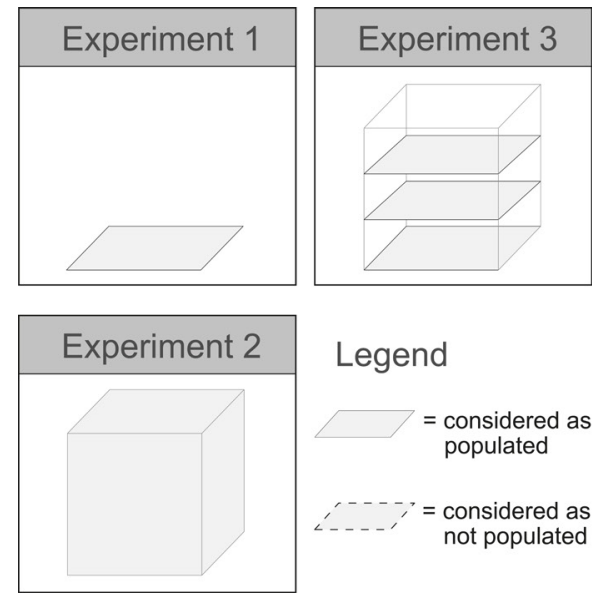

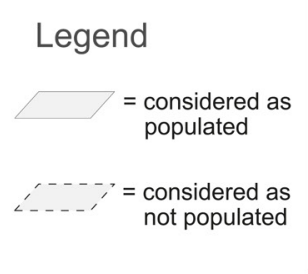

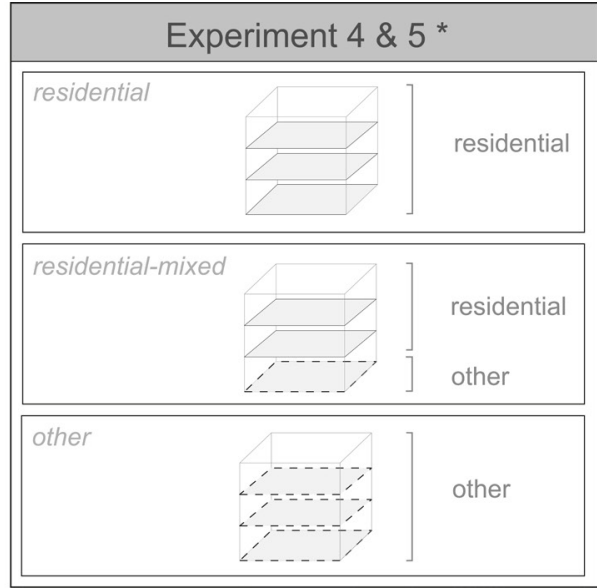

Figure 5. Schematic illustration showing the five experiments that were conducted for population estimation at single building level: using for experiment 1) the 2D building dataset containing the building footprints, experiment 2) the volume of the 3D building dataset, experiment 3 ) the 3D building dataset containing the number of the rounded floors, and the 3D building dataset with the extra information on the accompanied land use $\left(^{*}\right)$ based on volume for experiment 4 and rounded estimated floors for experiment 5

\subsection{Validation}

The VHR airborne DSM was used as a reference to validate the height of the 3D city model's features. The VHR DSM served to create an nDSM based on an algorithm by Pijl et al. (2020). The mean of the VHR nDSM pixel values was used to retrieve the height per building. Based on this, an object-based accuracy assessment was carried out given the overall deviation in terms of the mean absolute error (MAE). Additionally, we present an in-depth accuracy assessment based on the absolute percent error (APE) comparing the VHR nDSM and the SPOT nDSM. The APE is defined as the elementwise absolute percent difference between two numeric vectors and gives the deviation (Frasco, Hamner, \& 
LeDell, 2018).

To determine the accuracy of the population estimation, we used the census data for Santiago as a reference. The validation is performed at two spatial scales: manzanas and districts. This 1) enables to determine possible differences in methodological accuracy for small (manzanas) and large entities (districts), and 2) helps to identify the best method (experiment 1, 2, 3, 4 or 5) for future applications. We compare the reference and estimated values in total represented as scatterplots, and present the MAE and relative absolute error (RAE) as accuracy metrics. The RAE computes the relative absolute error between two numeric vectors (Frasco et al., 2018). For the best performing method in predicting population, we provide an in-depth accuracy analysis, comparing the error metric based on land-use proportions.

\section{$5 \quad$ Results}

\subsection{D City model}

An exemplary part of the created 3D city model shows the Central Business District (CBD) of Santiago's city center (Figure 6). The resulting 3D model depicts the different structures within this area, having the highest buildings within the CBD and smoothly fading out to the surrounding area.

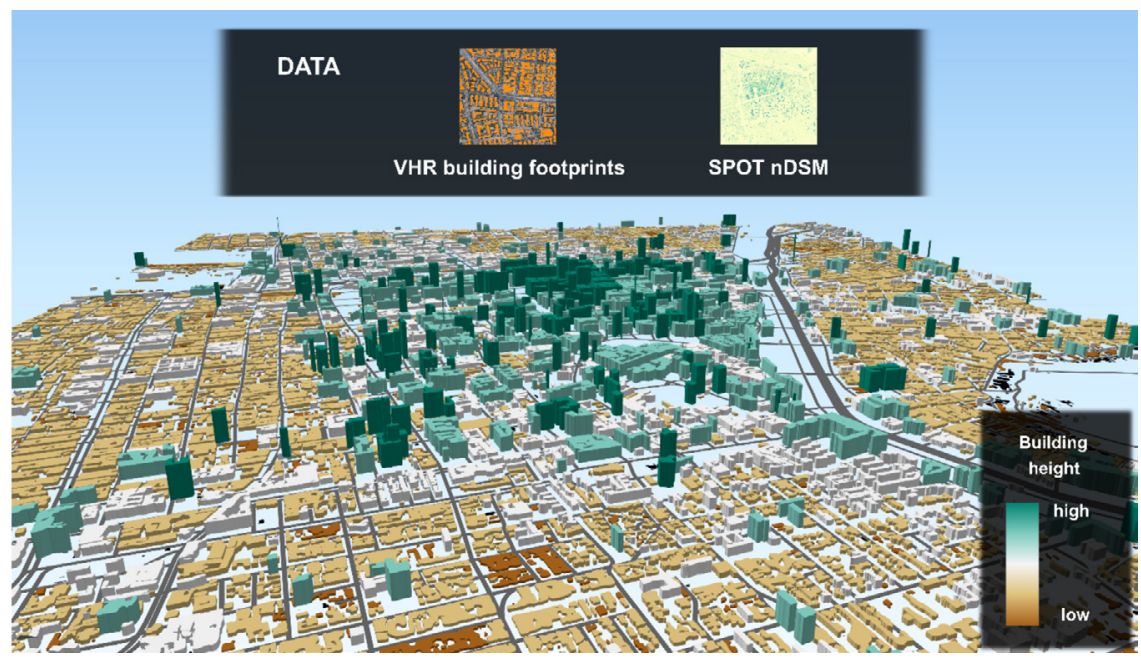

Figure 6. Exemplary illustration of the 3D model, showing the CBD of Santiago

For validating the height information of the 3D model, we tested the accuracy of the large-scale HR SPOT-7 nDSM against the airborne VHR nDSM that was available for a part of Santiago. The mean absolute error revealed that the height of buildings varies in average with $2.90 \mathrm{~m}$ from the VHR reference data $(\mathrm{MAE}=2.90)$. An in-depth accuracy analysis demonstrated that the APE decreases with increasing building height and building area (Figure 7). This means that the estimated building height from the HR SPOT nDSM was more accurate for higher and larger buildings. 

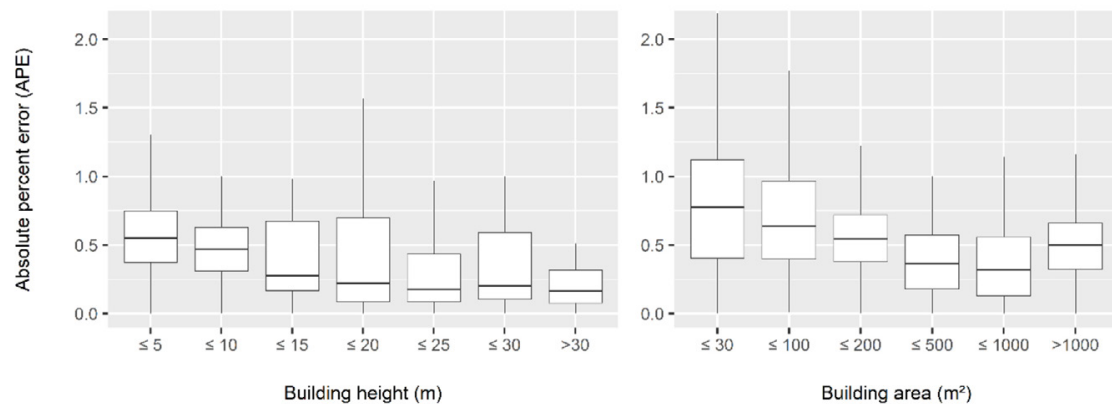

Figure 7. Boxplots showing the APE for different groups ( $\mathrm{x}$-axis) of building height in $\mathrm{m}$ (left) and building area in $\mathrm{m}^{2}$ (right). The $y$-axis is showing the value of APE.

\subsection{Deriving building floors}

With the building floor sample based on 100 Google Street View observations we were able to build a robust linear regression model (adj. $\mathrm{R}^{2}$ : 0.88, p-value: 2.2e-16) (Figure 8). Given an intercept of 0.69 , the linear regression revealed that an average height of $2 \mathrm{~m}$ in the height model corresponds to one floor (slope $=0.50$; being $1 \mathrm{~m}$ building height $=0.50$ floors). The resulting slope of the linear model can be interpreted as the number of floors which corresponds to $1 \mathrm{~m}$ of building height. The value of $2 \mathrm{~m}$ can be understood as the relative floor height within our model, but not the absolute average height of floors in Santiago de Chile.

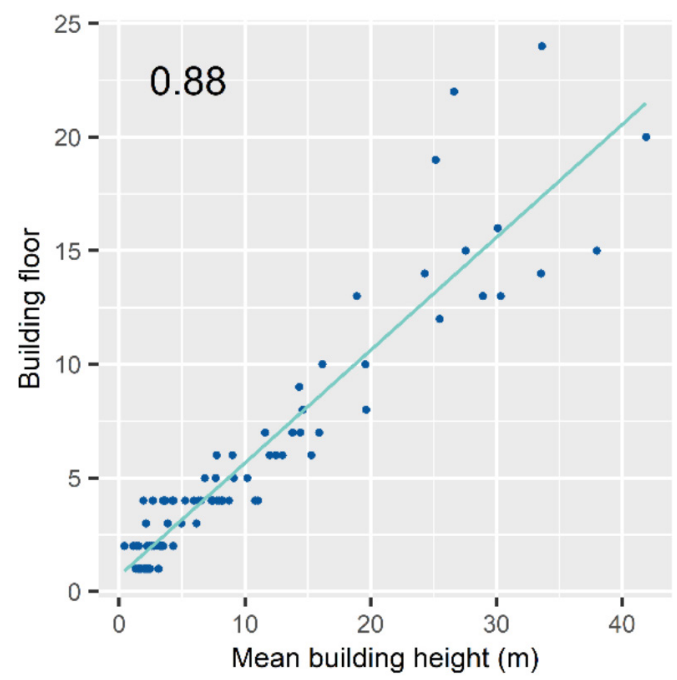

Figure 8. Results from the regression analysis revealing the relation of building floors and mean building height $(\mathrm{m})$ of the building sample (adj. $\mathrm{R}^{2}$ : 0.88, p-value: $2.2 \mathrm{e}-16$ )

\subsection{Intra-urban land use}

The acquired land use at single building level is shown in Figure 9. As described in Section 4.3, we have determined twelve final land-use classes for the study area. For reasons of clarity, and to concise to the most prominent land-use types, we limited the land use to five classes for the land-use mapping in Figure 9. The spatial distribution of land-use types differed remarkably throughout the city area. Within the center, there was a high density of land-use type "residential-mixed," whereas the most prominent landuse class in the outskirts of Santiago was the class "residential." "Residential" was the most prominent land-use class in our analysis with about $83 \%$ of all buildings and $75 \%$ of the total building area. 


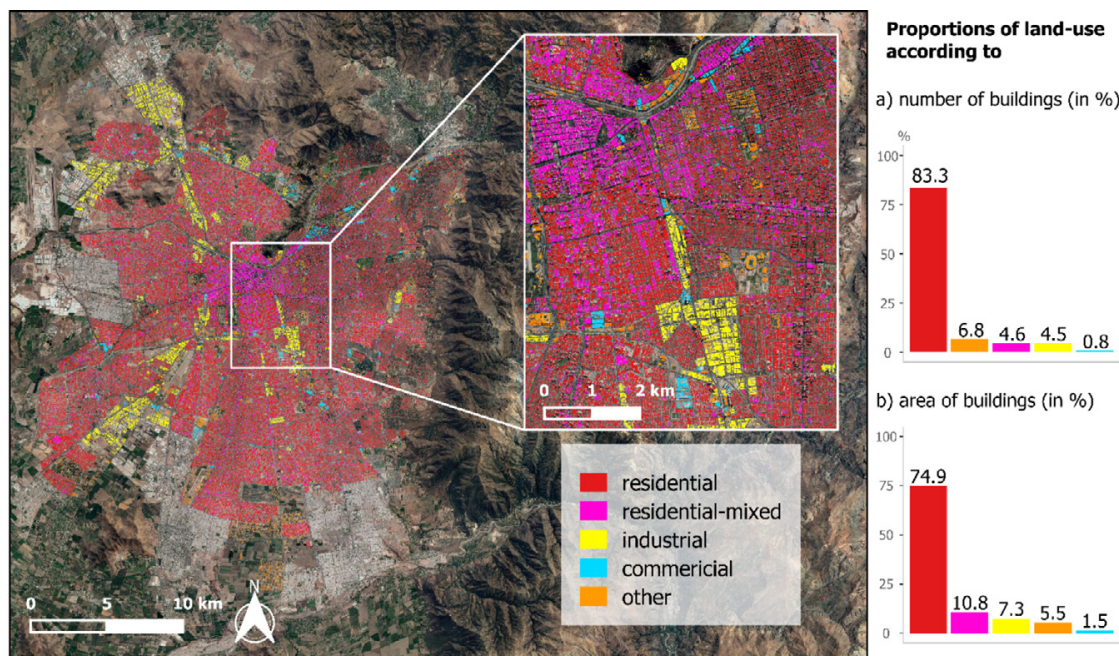

Figure 9. Map showing the identified land use at single building level for Santiago de Chile based on the applied OSM data workflow. The bar charts indicate the classified land-use proportions in regard to the total building number (a), and the total building area (b). The class "other" refers to "commercial-mixed," "industrial-mixed," "accommodation," "education," "cultural," "health," and "no land use."

\subsection{Population estimation}

For the overall accuracy metrics, we used the MAE and the RAE for the two spatial entities "manzanas" and "districts" (Table 4). The MAE presents the average absolute deviation in number of people between the predicted population and the population from the census data. The values can be understood as total persons. The RAE compares the mean residuals of the tested model to the mean residuals of a naive model. A reasonable model will result in a RAE of less than 1 (Cichosz, 2015). Our findings revealed that experiment 5 is the most accurate of all tested approaches for both spatial scales. However, at the district level, experiment 1 performed equally considering the RAE (RAE=0.74). Nevertheless, experiment 5 performed better in regard to the MAE. The lowest accuracy was yielded by experiment 2 .

The accuracy assessment of the five experiments revealed a contrary picture on the two spatial scales, when comparing the estimated population versus the census reference data (Figure 10). On the fine granular basis of the manzanas, the area-based (experiment 1), 3D (experiment 2) and floor-based (experiment 3) approaches revealed a poor performance. These three approaches underestimated clearly the actual population number. The accordance increased significantly when adding land-use information (experiment 4 and 5; adj. $\mathrm{R}^{2}: 0.38$ and 0.40 , respectively). At the level of districts, the best performing approach was experiment 5 (adj. $\left.R^{2}: 0.52\right)$, closely followed by experiment 1 (adj. $\left.R^{2}: 0.50\right)$. Experiment 4 did also perform well (adj. $\mathrm{R}^{2}$ : 0.40). Least performative were experiment 2 and 3 (adj. $\mathrm{R}^{2}: 0.26$ and 0.32 , respectively).

Figure 11 depicts the effect of different land-use types on the accuracy of the population estimation. The APE decreased with an increasing proportion of the land-use type "residential," either for manzanas or for districts. On the other hand, the error increased for the class "residential-mixed," similarly to the classes "other" and "no land use." 
Table 4. Overall accuracy metrics showing the mean absolute error (MAE) and relative absolute error (RAE) for the results of the population estimation for all five experiments. The MAE is given in number of persons.

\begin{tabular}{lcccc}
\hline & \multicolumn{2}{c}{ MAE } & \multicolumn{2}{c}{ RAE } \\
\hline & Manzanas & Districts & Manzanas & Districts \\
\hline Experiment 1 & 87.2 & 4929.9 & 0.84 & 0.74 \\
Experiment 2 & 110.8 & 7772.2 & 1.07 & 1.18 \\
Experiment 3 & 101.7 & 6638.8 & 0.98 & 1.00 \\
Experiment 4 & 85.3 & 6070.1 & 0.83 & 0.92 \\
Experiment 5 & $\mathbf{7 8 . 9}$ & $\mathbf{4 8 8 8 . 4}$ & $\mathbf{0 . 7 6}$ & $\mathbf{0 . 7 4}$ \\
\hline
\end{tabular}
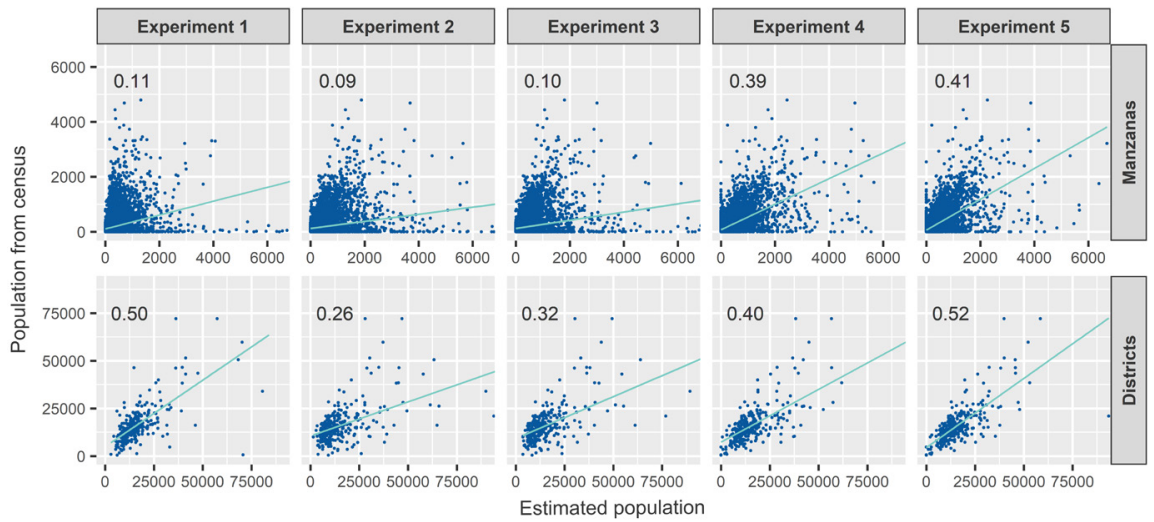

Figure 10. Scatterplots showing the values of the estimated population on the $y$-axis and the population from census validation data on the $\mathrm{x}$-axis for manzanas (top) and districts (bottom) for all five experiments



Figure 11. Boxplots showing the absolute percent error (APE) in relation to land-use proportions (\%) for the classes "residential," "residential-mixed," "other" and "no land use" on two different spatial scales (manzanas and districts). The error metrics were retrieved from population estimation based on experiment 5 . 


\section{Discussion}

In this study we aimed at deriving three key parameters for transportation analyses in cities: 1) buildings, as a minimal spatial unit where trips begin and end with 2) detailed land-use information, e.g., to predict travel behavior, and 3) the accompanied population, e.g., to estimate travel demand. We showed that these input data can be generated anywhere across the globe:

- extract city-wide VHR building footprints using a deep learning classification procedure using freely available RGB imagery (Stiller et al., 2019b),

- add building attributes, i.e., height information from HR tri-stereo imagery to obtain 3D features, and number of floors from Google Street View (discussed in Section 6.1),

- retrieve detailed land use from OSM data at single building level, which is available on large scales (discussed in Section 6.2),

- $\quad$ estimate the population at single building level by using a top-down approach requiring only one total population number at municipality level for the study area to determine intra-urban population patterns (discussed in Section 6.3).

Santiago de Chile served exemplary for any global city. The presented approach is transferrable and can be applied on large scales to gather base data for transportation planning concerning the urban spatial structure, including 3D buildings accompanied by the number of floors, land use, and population. The use of remote sensing data and methods has the clear advantage of providing objective insights and data for transportation research. Relevant data are missing for many places on Earth, especially in developing regions (Yuan et al., 2018). The proposed approach can help to overcome these imbalances of data availability in the context of transportation analysis. This is a relevant aspect, as urbanization and population growth are especially prominent in developing countries - two important factors for the increase in urban transportation demand - while facing a lack in data quantity and quality.

\subsection{D city model: creating Level-1 and Level-2 data}

We combined VHR 2D building footprint data with a resolution of $0.35 \mathrm{~m}$ with comparatively coarse HR SPOT-7 data with a resolution of $2 \mathrm{~m}$. The advantage of this procedure guarantees to have the high accuracy and exact location of building features at a VHR and add height information for the entire study area. The relatively coarse resolution of SPOT-7 data caused inaccuracies in the assignment of building heights. However, the validation with the VHR nDSM showed an average absolute error of $2.90 \mathrm{~m}$, being a deviation of less than 1.5 building floors. Analyzing the vertical accuracies revealed that the higher or larger a building, the smaller is the height error. This observation is in line with prior studies comparing large-area satellite-based DSMs with high resolution reference data (Wurm et al., 2014). On the one hand, this effect was specifically prominent in small housing areas with a low floor number, e.g., in residential areas apart from the city center. On the other hand, the effect became less influential for larger and higher buildings, e.g., building units within dense, and highly populated urban areas. Moreover, the orthophoto mosaic contained several different perspectives, from which the building footprints have been retrieved. This caused inconsistencies within the approach, so façades of buildings were erroneously included in the footprint area. Consequently, this effect caused an overestimation of building area. However, the fusion of data from different sensors in conjunction with different geometric resolutions is challenging (Stiller, Ottinger, \& Leinenkugel, 2019a). Mapping the used building data $(0.35 \mathrm{~m})$ and the SPOT $\mathrm{nDSM}(2 \mathrm{~m})$ revealed that general patterns are matching but do also show shifts of the locations. Taking all these inaccuracies into account, the proposed workflow generated a 3D citywide model with minor height deviations in an acceptable range able to derive buildings, which serve as objects where trips originate and end (Sevtsuk \& Mekonnen, 2012). 
Google Street View served to estimate the number of floors in relation to the mean building height based on a linear regression approach. For this, the number of floors was sampled from Google Street View imagery for a total of 100 buildings. This resulted in a robust linear regression model. Although the sampled buildings have been distributed across different building types and within different areas throughout the study area, this generalized assumption does not distinguish between differences in local building styles or land-use type. In reality, floor heights differ within land-use types, e.g., in the U.S. residential ceiling heights are assumed to be 2.4 and the overall floor heights for commercial and industrial uses is about $3.4 \mathrm{~m}$ (Zhang, Zhao, \& Sutherland, 2013).

\subsection{Land-use assignment: creating Level-3 data}

For determining land use, we relied on open crowd-sourced data from OSM. We are aware that crowdsourced data have different levels of accuracy and completeness (Senaratne, Mobasheri, Ali, Capineri, $\&$ Haklay, 2016). However, OSM data have the advantage of determining a higher level of detail that would not be possible, e.g., by using only remote sensing data (Fonte et al., 2017; Schultz et al., 2017). In addition, OSM data were found to serve as a reasonable alternative for identifying land use apart from authoritative datasets (Arsanjani, Mooney, Zipf, \& Schauss, 2015). A detailed land-use classification for entire Santiago was possible through the combination of the land-use polygons and the more detailed POIs. This guarantees for a city-wide land-use determination while having the ability to achieve a more detailed classification of land use, both being advantageous for transportation analysis to include all aspects of the transportation system within an entire metropolitan area. In addition, both OSM datasets are available for many places throughout the world, allowing for transferability of the approach to other cities. By adding land-use information, we found that the accuracy of the population distribution increased, which was also confirmed by (Biljecki et al., 2016) and is discussed in more detail in the next section.

\subsection{Population estimation: creating Level-4 data}

Here we discuss our findings based on the two spatial units we considered: manzanas and districts. Adding land-use information was a crucial step on the scale of block-level entities (manzanas), as this showed a strong increase in accuracy. Using data with a lower level of detail, all other experiments performed less accurate. Thus, if small-scale intra-urban population distribution is needed for the purpose of transportation planning or modelling, land use seems to play an indispensable role, whereby approaches using solely remote sensing come up against their limits (experiment 1 and 2). Without land use, population appeared to be underestimated significantly (Figure 6). For example, TAZs are common units for transportation models (Nordenholz et al., 2019). Their size is not consistent and varies throughout different administrations and within space, as it is defined through population counts. Thereby, TAZ sizes vary strongly, and can range from building-level within city centers, to block-level or even district-level in the outskirts (Harvey, 2002). Within this study, population was determined at the single building level. Therefore, it can be spatially aggregated to larger entities, e.g., administrative boundaries, TAZs or any desired grid cell size. This might also be of special interest for transportation research, as relevant input data do not follow unified spatial standards, e.g., TAZs (Martínez, Viegas, \& Silva, 2009).

For larger spatial scales (districts), experiment 5 was the most accurate in predicting population using estimated building floors and land-use information. Nevertheless, experiment 1 using only remote sensing based $2 \mathrm{D}$ data performed similarly in predicting the population number. This finding is in accordance with other studies, which found a good relation of built-up area and population numbers (Harvey, 2002; Wu, Wang, \& Qiu, 2008). Therefore, using only remote sensing data is an applicable 
approach at the district scale, being a great alternative, as it requires less data, computation and time. We obtained a city-wide estimation of the number of floors at single building level with a reasonable regression model, by only using 100 sampled buildings. However, using the 3D and building floor dataset (experiment 2 and experiment 3) showed a poor performance and even fell short of using solely 2D data derived from remote sensing. For this reason, we recommend increasing the number of sampled buildings, which might help to increase the accuracy rates for population estimation tasks, when using $3 \mathrm{D}$ floor data. To sum up, using only remote sensing can be understood as a reasonable proxy anywhere across the world for assessing population at district scales, whereas using further geo-data achieves better results at building block level (manzanas) but is less applicable across the globe.

The validation procedure for the experiments revealed that some entities can be considered as extreme outliers. This had strong effects on the overall accuracy of the evaluated experiments. We identified the CBD as a strong outlier for the population estimation at the district scale based on experiment 4 and 5. This outlier had a strong effect on the overall accuracy of the final result, as it massively overestimated population giving a population count of about 120,000 (experiment 4) and 90,000 (experiment 5), while the reference census data revealed a population number of approximately 20,000. Experiment 1 , which uses only remote sensing data, performed reasonably well with an estimated population count of about 17,000. This agrees with other studies, which found a good correspondence of area and population within relatively homogenous areas with similar building height (Wu et al., 2008). The CBD of Santiago is also characterized by relatively constant building heights. Therefore, using solely remote sensing to estimate population in those built environments served as an alternative to highly detailed data (experiment 4 and 5). A possible reason for the overestimation by experiment 4 and 5 within the $\mathrm{CBD}$ is that it exhibited relatively large and high buildings, resulting in a high potential dwelling area. Additionally, according to the OSM workflow the classes "residential" and "residential-mixed" were determined, following in a high estimated population number (Figure 12a). Moreover, the presented results revealed that the error rate increased with the proportion of the land use "residential-mixed" at both, the manzana and district level. Steinnocher, Bono, Chatenoux, Tiede, \& Wendt, (2019) found that a highly accurate delineation between residential and non-residential areas is significant for accurate population estimation. The CBD was one extreme example within our study area for this phenomenon. Eliminating this outlier increased the overall accuracy significantly based on experiment 5 (Figure 12b; $\mathrm{R}^{2}$ : 0.61; p-value: $<2.2 \mathrm{e}-16$ ). Therefore, we recommend adapting the factor for distributing population for class "residential-mixed" to decrease their influence as dwelling units, and thus to increase the overall accuracy of estimating population at single building level.

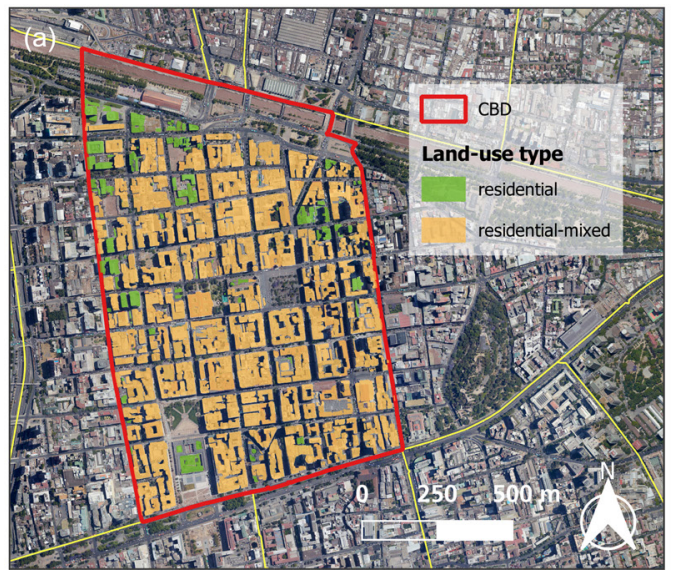

(b)

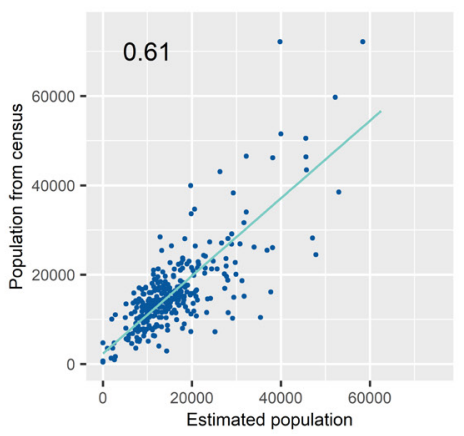

Figure 12. (a) Map of the CBD and classified buildings with accompanied land use, and (b) scatterplot of experiment 5 at district scale after removing the "outlier" CBD ( $\mathrm{R}^{2}$ : 0.61 ; p-value: $\left.<2.2 \mathrm{e}-16\right)$ 


\section{Conclusion}

Our study aimed at presenting a generic approach to generate relevant data for transportation models in urban planning and research, specifically addressing three important factors of the urban spatial structure: buildings, land use, and intra-urban population distribution. Through its transferability it is not limited to any specific or unique type of city or region and it is independent from official data.

We conclude with the following five key aspects from our study:

- Filling the gap of missing geo-data: using deep-learning based classification approaches help to extract relevant geo-data from airborne or remote sensing imagery with a high level of accuracy

- Data fusion for robust 3D city models: depict the physical characteristics of the urban spatial structure and achieve a higher overall level of detail through the combination of data with different levels of spatial resolution

- Combine remote sensing derived building footprints with OSM: determine detailed land use from various OSM datasets at the single building level

- Depending on the scale of analysis: include land use for more accurate population estimation for smaller entities (here: manzanas with an average size of approximately $120 \times 120 \mathrm{~m}$ ); remote sensing based approaches are sufficient for larger entities (here: districts approximately $1,600 \times 1,600 \mathrm{~m})$

- The combination of remote sensing data and techniques with open geo-data can help to push forward data availability in the field of urban transportation, especially in developing countries

The three investigated parameters of the urban spatial structure are of special interest in the context of urban transportation systems. When relevant data on these key parameters are not available or traditional methods come up against limiting factors, the proposed approach might serve as an alternative to support transportation planning and research towards a more sustainable and effective urban transportation system. This is of particular importance in the face of global urbanization, where highest urban growth rates exist in non-developed countries, causing explosive increase in transportation demand, requiring reliable and large-area baseline data.

\section{$8 \quad$ Author contributions}

DS, MW: Conceptualization, Project administration, Investigation, Validation, Roles/Writing - original draft; DS, TS, PA, KS: Data curation, Formal analysis; DS, TS, PA: Software; DS, MW, TS, PA: Methodology; DS: Visualization; DS, MW, HT: Writing - review \& editing; MW, SD, HT: Resources, Supervision; MW, HT: Funding acquisition.

\section{$9 \quad$ Funding}

The authors acknowledge the financial funding by the German Federal Government and the Helmholtz-Gesellschaft as part of the project "Transport and Climate (TraK)." This research was also funded in part by the German Federal Ministry of Education and Research (BMBF) under grant no. 03G0876 (project RIESGOS). 


\section{Acknowledgements}

We thank Ihab Kaddoura for profound discussions and helpful support. In our analyses we used map data copyrighted by OpenStreetMap contributors and available from https://www.openstreetmap.org. We also want to thank the anonymous reviewers for very helpful comments on the initial version of the paper.

\section{Declarations of interest}

None 


\section{References}

Aljoufie, M., Zuidgeest, M., Brussel, M., \& van Maarseveen, M. (2013). Spatial-temporal analysis of urban growth and transportation in Jeddah City, Saudi Arabia. Cities, 31, 57-68. https:// doi.10.1016/j.cities.2012.04.008

Angel, S., Parent, J., Civco, D. L., Blei, A., \& Potere, D. (2011). The dimensions of global urban expansion: Estimates and projections for all countries, 2000-2050. Progress in Planning, 75(2), 53-107. htpps://doi.10.1016/j.progress.2011.04.001

Arsanjani, J. J., Mooney, P., Zipf, A., \& Schauss, A. (2015). Quality assessment of the contributed land-use information from OpenStreetMap versus authoritative datasets. Lecture Notes in Geoinformation and Cartography (pp. 37-58). Basel, Switzerland: Springer International Publishing. https:// doi.10.1007/978-3-319-14280-7_3

Barrington-Leigh, C., \& Millard-Ball, A. (2017). The world's user-generated road map is more than 80\% complete. PLOS One, 12(8), e0180698. https://doi.10.1371/journal.pone.0180698

Biljecki, F., Ohori, K. A., Ledoux, H., Peters, R., \& Stoter, J. (2016). Population estimation using a 3D city model: A multi-scale country-wide study in the Netherlands. PLOS One, 11(6). https:// doi.10.1371/journal.pone. 0156808

Bittner, K., Cui, S., \& Reinartz, P. (2017). Building extraction from remote sensing data using fully convolutional networks. ISPRS - International Archives of the Photogrammetry, Remote Sensing and Spatial Information Sciences, 42, 481-486. https://doi.10.5194/isprs-archives-xlii-1-w1-481-2017

Bowen, B., Vlasek, K., \& Webb, C. (2004). An assessment of remote sensing applications in transportation. Paper presented at the 2004 Annual Forum of the Transportation Research Forum. https://www.ugpti.org/smartse/research/citations/downloads/Bowen-Assessment_of_RS_in_Transportation-2004. pdf

Brovelli, M., \& Zamboni, G. (2018). A new method for the assessment of spatial accuracy and completeness of OpenStreetMap building footprints. ISPRS International Journal of Geo-Information, 7(8), 289. https://doi.10.3390/ijgi7080289

Cao, X., Næss, P., \& Wolday, F. (2019). Examining the effects of the built environment on auto ownership in two Norwegian urban regions. Transportation Research Part D: Transport and Environment, 67, 464-474. https://doi.10.1016/j.trd.2018.12.020

Cervero, R. B. (2013). Linking urban transport and land use in developing countries. Journal of Transport and Land Use, 6(1), 7. https://doi.10.5198/jtlu.v6i1.425

Chen, T., Hui, E. C. M., Wu, J., Lang, W., \& Li, X. (2019). Identifying urban spatial structure and urban vibrancy in highly dense cities using georeferenced social media data. Habitat International, 89, 102005. https://doi.10.1016/j.habitatint.2019.102005

Cheng, L., Chen, X., Yang, S., Cao, Z., Vos, J. D., \& Witlox, F. (2019). Active travel for active aging in China: The role of built environment. Journal of Transport Geography, 76, 142-152. https:// doi.10.1016/j.jtrangeo.2019.03.010

Choi, K., \& Zhang, M. (2017). The impact of metropolitan, county, and local land use on driving emissions in US metropolitan areas: Mediator effects of vehicle travel characteristics. Journal of Transport Geography, 64, 195-202. https://doi.10.1016/j.jtrangeo.2017.09.004

Choupani, A.-A., \& Mamdoohi, A. R. (2016). Population synthesis using iterative proportional fitting (IPF): A review and future research. Transportation Research Procedia, 17, 223-233. https:// doi.10.1016/j.trpro.2016.11.078

Cichosz, P. (2015). Data mining algorithms: Explained. Hoboken, NJ: John Wiley \& Sons.

d'Angelo, P., \& Reinartz, P. (2011). Semiglobal matching results on the ISPRS stereo matching bench- 
mark. ISPRS - International Archives of the Photogrammetry, Remote Sensing and Spatial Information Sciences, 38(4), 79-84. https://doi.10.5194/isprsarchives-xxxviii-4-w19-79-2011

de Sherbinin, A., Balk, D., Yager, K., Jaiteh, M., Pozzi, F., Giri, C., \& Wannebo, A. (2002). Social science applications of remote sensing. A CIESIN thematic guide. Palisades, NY: Center for International Earth Science Information Network of Columbia University. http://sedac.ciesin.columbia.edu/tg/ guide_main.jsp

Dincer, S. E., Akdemir, F., Ulvi, H., \& Duzkaya, H. (2019). Assessing urban sprawl effect of transportation investments using remote sensing data and GIS methods: The case of Ankara protocol road. IOP Conference Series: Materials Science and Engineering, 471, 092079. https://doi.10.1088/1757899x $/ 471 / 9 / 092079$

Duncan, M. J., Winkler, E., Sugiyama, T., Cerin, E., duToit, L., Leslie, E., \& Owen, N. (2010). Relationships of land-use mix with walking for transport: Do land uses and geographical scale matter? Journal of Urban Health, 87(5), 782-795. https://doi.10.1007/s11524-010-9488-7

Estima, J., \& Painho, M. (2015). Investigating the potential of OpenStreetMap for land use/land cover production: A case study for continental Portugal. In Lecture notes in Geoinformation and Cartography (pp. 273-293). Basel, Switzerland: Springer International Publishing. https://doi.10.1007/9783-319-14280-7_14

Faghih-Imani, A., Eluru, N., El-Geneidy, A. M., Rabbat, M., \& Haq, U. (2014). How land use and urban form impact bicycle flows: Evidence from the bicycle-sharing system (BIXI) in Montreal. Journal of Transport Geography, 41, 306-314. https://doi.10.1016/j.jtrangeo.2014.01.013

Fan, H., Zipf, A., Fu, Q., \& Neis, P. (2014). Quality assessment for building footprints data on OpenStreetMap. International Journal of Geographical Information Science, 28(4), 700-719. https://doi.10 $.1080 / 13658816.2013 .867495$

Farber, S., \& Li, X. (2013). Urban sprawl and social interaction potential: An empirical analysis of large metropolitan regions in the United States. Journal of Transport Geography, 31, 267-277. https:// doi.10.1016/j.jtrangeo.2013.03.002

Fonte, C., Minghini, M., Patriarca, J., Antoniou, V., See, L., \& Skopeliti, A. (2017). Generating up-todate and detailed land use and land cover maps using OpenStreetMap and GlobeLand30. ISPRS International Journal of Geo-Information, 6(4), 125. https://doi.10.3390/ijgi6040125

Frasco, M., Hamner, B., \& LeDell, E. (2018). Metrics: Evaluation metrics for machine learning. https:// CRAN.R-project.org/package=Metrics

Ghanea, M., Moallem, P., \& Momeni, M. (2016). Building extraction from high-resolution satellite images in urban areas: Recent methods and strategies against significant challenges. International Journal of Remote Sensing, 37(21), 5234-5248. https://doi.10.1080/01431161.2016.1230287

Glaeser, E. (2011). Triumph of the city: How our greatest invention makes us richer, smarter, greener, healthier, and happier. London: Penguin Press HC.

Grange, L. de, \& Troncoso, R. (2011). Impacts of vehicle restrictions on urban transport flows: The case of Santiago, Chile. Transport Policy. https://doi.10.1016/j.tranpol.2011.06.001

Guindon, B., \& Zhang, Y. (2007). Using satellite remote sensing to survey transport-related urban sustainability. International Journal of Applied Earth Observation and Geoinformation, 9(3), 276-293. https://doi.10.1016/j.jag.2006.09.006

Harvey, J. T. (2002). Estimating census district populations from satellite imagery: Some approaches and limitations. International Journal of Remote Sensing, 23(10), 2071-2095. doi.10.1080/01431160110075901

Hecht, R., Kunze, C., \& Hahmann, S. (2013). Measuring completeness of building footprints in OpenStreetMap over space and time. ISPRS International Journal of Geo-Information, 2(4), 1066-1091. 
https://doi.10.3390/ijgi2041066

Hu, H., Xu, J., Shen, Q., Shi, F., \& Chen, Y. (2018). Travel mode choices in small cities of China: A case study of Changting. Transportation Research Part D: Transport and Environment, 59, 361-374. https://doi.10.1016/j.trd.2018.01.013

Hui, J., Du, M., Ye, X., Qin, Q., \& Sui, J. (2019). Effective building extraction from high-resolution remote sensing images with multitask driven deep neural network. IEEE Geoscience and Remote Sensing Letters, 16(5), 786-790. https://doi.10.1109/lgrs.2018.2880986

Humanity \& Inclusion. (2019). Mapping challenge. Building missing maps with machine learning. CrowdAI/Mapping Challenge. https:/www.crowdai.org/challenges/mapping-challenge

Ihlanfeldt, K. (2020). Vehicle miles traveled and the built environment: New evidence from panel data. Journal of Transport and Land Use, 13(1), 23-48. https://doi.10.5198/jtlu.2020.1647

Infraestructura de Datos Geoespeciales (IDE) Chile. (2019). Fotografía aérea del Gran Santiago año 2014. http://www.ide.cl/index.php/imagenes-y-mapas-base/item/1577-fotografia-aerea-del-gransantiago-ano-2014

Instituto Nacional de Estadísticas (INE) Chile. (2017). Censo de población y vivienda. https://www. ine.cl/estadisticas/sociales/censos-de-poblacion-y-vivienda/poblacion-y-vivienda

Jin, J. (2019). The effects of labor market spatial structure and the built environment on commuting behavior: Considering spatial effects and self-selection. Cities, 95, 102392. https://doi.10.1016/j. cities.2019.102392

Kaddoura, I., Kröger, L., \& Nagel, K. (2016). User-specific and dynamic internalization of road traffic noise exposures. Networks and Spatial Economics, 17(1), 153-172. https://doi.10.1007/s11067-0169321-2

Kopsiaftis, G., \& Karantzalos, K. (2015). Vehicle detection and traffic density monitoring from very high resolution satellite video data. Paper presented at the 2015 IEEE International Geoscience and Remote Sensing Symposium (IGARSS). https://doi.10.1109/igarss.2015.7326160

Krauß, T. (2014). Six years operational processing of satellite data using CATENA at DLR: Experiences and recommendations. Kartographische Nachrichten, 64, 74-80. https://doi.10.1007/BF035441 17

Krehl, A., Siedentop, S., Taubenböck, H., \& Wurm, M. (2016). A comprehensive view on urban spatial structure: Urban density patterns of German city regions. ISPRS International Journal of GeoInformation, 5(6), 76. https://doi.10.3390/ijgi5060076

Lee, S., \& Lee, B. (2020). Comparing the impacts of local land use and urban spatial structure on household VMT and GHG emissions. Journal of Transport Geography, 84, 102694. https://doi.10.1016/j. jtrangeo.2020.102694

Lehmann, F., Berger, R., Brauchle, J., Hein, D., Meissner, H., Pless, S.,... Wieden, A. (2011). MACS Modular Airborne Camera System for generating photogrammetric high-resolution products. Photogrammetrie - Fernerkundung - Geoinformation, 2011(6), 435-446. https://doi.10.1127/1432$8364 / 2011 / 0096$

Levashev, A. (2017). Application of geoinformation technologies for the transportation demand estimation. Transportation Research Procedia, 20, 406-411. https://doi.10.1016/j.trpro.2017.01.066

Liddle, B. (2013). Urban density and climate change: A STIRPAT analysis using city-level data. Journal of Transport Geography, 28, 22-29. https://doi.10.1016/j.jtrangeo.2012.10.010

Linton, C., Grant-Muller, S., \& Gale, W. F. (2015). Approaches and techniques for modelling $\mathrm{CO}_{2}$ emissions from road transport. Transport Reviews, 35(4), 533-553. https://doi.10.1080/01441647 .2015 .1030004

Ma, L., Liu, Y., Zhang, X., Ye, Y., Yin, G., \& Johnson, B. A. (2019). Deep learning in remote sensing applications: A meta-analysis and review. ISPRS Journal of Photogrammetry and Remote Sensing, 152, 
166-177. https://doi.10.1016/j.isprsjprs.2019.04.015

Machado, C. A. S., \& Quintanilha, J. A. (2019). Identification of trip generators using remote sensing and geographic information system. Transportation Research Interdisciplinary Perspectives, 3, 100069. https://doi.10.1016/j.trip.2019.100069

María, H. S., Hube, M. A., Rivera, F., Yepes-Estrada, C., \& Valcárcel, J. A. (2016). Development of national and local exposure models of residential structures in Chile. Natural Hazards, 86(S1), 55-79. https://doi.10.1007/s11069-016-2518-3

Martínez, L. M., Viegas, J. M., \& Silva, E. A. (2009). A traffic analysis zone definition: A new methodology and algorithm. Transportation, 36(5), 581-599. https://doi.10.1007/s11116-009-9214-z

Nordenholz, F., Metzler, S., \& Winkler, C. (2019). An automated gradual zoning approach for large-scale transport models. Procedia Computer Science, 151, 147-154. https://doi.10.1016/j. procs.2019.04.023

Nuhn, H., \& Hesse, M. (2006). Verkehrsgeographie. Paderborn: Ferdinand Schöningh GmbH.

Okokon, E., Turunen, A., Ung-Lanki, S., Vartiainen, A.-K., Tiittanen, P., \& Lanki, T. (2015). Roadtraffic noise: Annoyance, risk perception, and noise sensitivity in the Finnish adult population. International Journal of Environmental Research and Public Health, 12(6), 5712-5734. https:// doi.10.3390/ijerph120605712

OpenStreetMap contributors. (2017). Planet dump. https://planet.osm.org.

Palubinskas, G., Kurz, F., \& Reinartz, P. (2010). Model based traffic congestion detection in optical remote sensing imagery. European Transport Research Review, 2(2), 85-92. https://doi.10.1007/ s12544-010-0028-z

Parr, J. B. (2013). The regional economy, spatial structure and regional urban systems. Regional Studies, 48(12), 1926-1938. https://doi.10.1080/00343404.2013.799759

Perko, R., Raggam, H., Gutjahr, K. H., \& Schardt, M. (2015). Advanced DTM generation from very high resolution satellite stereo images. ISPRS Annals of Photogrammetry, Remote Sensing and Spatial Information Sciences, 2(3), 165-172. https://doi.10.5194/isprsannals-ii-3-w4-165-2015

Pijl, A., Bailly, J.-S., Feurer, D., Maaoui, M. A. E., Boussema, M. R., \& Tarolli, P. (2020). TERRA: Terrain extraction from elevation rasters through repetitive anisotropic filtering. International Journal of Applied Earth Observation and Geoinformation, 84, 101977. https://doi.10.1016/j.jag.2019.101977

Piltz, B., Bayer, S., \& Poznanska, A. M. (2016). Volume based DTM generation from very high resolution photogrammetric DSMS. ISPRS - International Archives of the Photogrammetry, Remote Sensing and Spatial Information Sciences, 41, 83-90. https://doi.10.5194/isprs-archives-XLI-B3-83-2016

Puertas, O. L., Henríquez, C., \& Meza, F. J. (2014). Assessing spatial dynamics of urban growth using an integrated land use model. Application in Santiago metropolitan area, 2010-2045. Land Use Policy, 38, 415-425. https://doi.10.1016/j.landusepol.2013.11.024

Resch, E., Bohne, R. A., Kvamsdal, T., \& Lohne, J. (2016). Impact of urban density and building height on energy use in cities. Energy Procedia, 96, 800-814. https://doi.10.1016/j.egypro.2016.09.142

Rodrigue, J.-P., Comtois, C., \& Slack, B. (2016). The geography of transport systems. Oxfordshire, England: Routledge, Taylor \& Francis Ltd.

Salvo, G., Caruso, L., Scordo, A., Guido, G., \& Vitale, A. (2017). Traffic data acquirement by unmanned aerial vehicle. European Journal of Remote Sensing, 50(1), 343-351. https://doi.10.1080/22 797254.2017.1328978

Sarlas, G., Páez, A., \& Axhausen, K. W. (2020). Betweenness-accessibility: Estimating impacts of accessibility on networks. Journal of Transport Geography, 84, 102680. https://doi.10.1016/j.jtrangeo.2020.102680

Schultz, M., Voss, J., Auer, M., Carter, S., \& Zipf, A. (2017). Open land cover from OpenStreetMap 
and remote sensing. International Journal of Applied Earth Observation and Geoinformation, 63, 206213. https://doi.10.1016/j.jag.2017.07.014

Senaratne, H., Mobasheri, A., Ali, A. L., Capineri, C., \& Haklay, M. (Muki). (2016). A review of volunteered geographic information quality assessment methods. International Journal of Geographical Information Science, 31(1), 139-167. https://doi.10.1080/13658816.2016.1189556

Sevtsuk, A., \& Mekonnen, M. (2012). Urban network analysis. A new toolbox for ArcGIS. Revue internationale de géomatique, 22(2), 287-305. https://doi.10.3166/rig.22.287-305

Sohn, J. (2005). Are commuting patterns a good indicator of urban spatial structure? Journal of Transport Geography, 13(4), 306-317. https://doi.10.1016/j.jtrangeo.2004.07.005

Soltani, A., \& Somenahalli, S. (2005). Household vehicle ownership: Does urban structure matter? Paper presented at the 28th Australasian Transport Research Forum, ATRF 05, Curtin University, Australia.

Srinivasan, S., Provost, R., \& Steiner, R. (2013). Modeling the land-use correlates of vehicle-trip lengths for assessing the transportation impacts of land developments. Journal of Transport and Land Use, 6(2), 59. https://doi.10.5198/jtlu.v6i2.254

Steinnocher, K., Bono, A. D., Chatenoux, B., Tiede, D., \& Wendt, L. (2019). Estimating urban population patterns from stereo-satellite imagery. European Journal of Remote Sensing, 52(sup2), 12-25. https://doi.10.1080/22797254.2019.1604081

Stevens, F. R., Gaughan, A. E., Linard, C., \& Tatem, A. J. (2015). Disaggregating census data for population mapping using random forests with remotely-sensed and ancillary data. PLOS One, 10(2), e0107042. https://doi.10.1371/journal.pone.0107042

Stevenson, M., Thompson, J., de Sá, T. H., Ewing, R., Mohan, D., McClure, R.,... Woodcock, J. (2016). Land use, transport, and population health: Estimating the health benefits of compact cities. The Lancet, 388(10062), 2925-2935. https://doi.10.1016/s0140-6736(16)30067-8

Stiller, D., Ottinger, M., \& Leinenkugel, P. (2019a). Spatio-temporal patterns of coastal aquaculture derived from Sentinel-1 time series data and the full Landsat archive. Remote Sensing, 11(14), 1707. https://doi10.3390/rs11141707

Stiller, D., Stark, T., Wurm, M., Dech, S., \& Taubenböck, H. (2019b). Large-scale building extraction in very high-resolution aerial imagery using Mask R-CNN. Paper presented at the 2019 Joint Urban Remote Sensing Event (JURSE), Vannes, France. https://doi.10.1109/jurse.2019.8808977

Sun, B., Ermagun, A., \& Dan, B. (2017). Built environmental impacts on commuting mode choice and distance: Evidence from Shanghai. Transportation Research Part D: Transport and Environment, 52, 441-453. https://doi.10.1016/j.trd.2016.06.001

Taubenböck, H., Kraff, N. J., \& Wurm, M. (2018). The morphology of the arrival city—A global categorization based on literature surveys and remotely sensed data. Applied Geography, 92, 150-167. https://doi.10.1016/j.apgeog.2018.02.002

Taubenböck, H., Roth, A., \& Dech, S. (2008). Linking structural urban characteristics derived from high resolution satellite data to population distribution. In V. Coors, M. Rumor, E. Fendel, \& S. Zlatanova (Eds.), Urban and regional data management, proceedings and monographs in engineering, water and earth sciences (pp. 35-45). Stuttgart, Germany: Urban Data Management Society.

Taubenböck, H., Weigand, M., Esch, T., Staab, J., Wurm, M., Mast, J., \& Dech, S. (2019). A new ranking of the world's largest cities-Do administrative units obscure morphological realities? Remote Sensing of Environment, 232, 111353. https://doi/10.1016/j.rse.2019.111353

Tian, Y., Zhou, Q., \& Fu, X. (2019). An analysis of the evolution, completeness and spatial patterns of OpenStreetMap building data in China. ISPRS International Journal of Geo-Information, 8(1), 35. https://doi.10.3390/ijgi8010035 
Tracy, A. J., Su, P., Sadek, A. W., \& Wang, Q. (2011). Assessing the impact of the built environment on travel behavior: A case study of Buffalo, New York. Transportation, 38(4), 663-678. https:// doi.10.1007/s11116-011-9337-x

United Nations. (2019). World urbanization prospects: The 2018 revision. New York: United Nations.

Van Acker, V., \& Witlox, F. (2010). Commuting trips within tours: How is commuting related to land use? Transportation, 38(3), 465-486. https://doi.10.1007/s11116-010-9309-6

Walker, J., Li, J., Srinivasan, S., \& Bolduc, D. (2010). Travel demand models in the developing world: Correcting for measurement errors. Transportation Letters, 2(4), 231-243. https://doi.10.3328/ t1.2010.02.04.231-243

Wang, Y., Mishra, S., Ye, X., Li, L., \& Wu, B. (2017). The application of integrated multimodal metropolitan transportation model in urban redevelopment for developing countries. Transportation Research Procedia, 25, 2990-3002. https://doi.10.1016/j.trpro.2017.05.378

Wu, S., Qiu, X., \& Wang, L. (2005). Population estimation methods in GIS and remote sensing: A review. GIScience \& Remote Sensing, 42(1), 80-96. https://doi.10.2747/1548-1603.42.1.80

Wu, S., Wang, L., \& Qiu, X. (2008). Incorporating GIS building data and census housing statistics for sub-block-level population estimation. The Professional Geographer, 60(1), 121-135. https:// doi.10.1080/00330120701724251

Wurm, M., d'Angelo, P., Reinartz, P., \& Taubenböck, H. (2014). Investigating the applicability of cartosat-1 DEMs and topographic maps to localize large-area urban mass concentrations. IEEE Journal of Selected Topics in Applied Earth Observations and Remote Sensing, 7(10), 4138-4152. https:// doi.10.1109/jstars.2014.2346655

Wurm, M., Droin, A., Stark, T., Geiß, C., Sulzer, W., \& Taubenböck, H. (2021). Deep learning-based generation of building stock data from remote sensing for urban heat demand modeling. ISPRS International Journal of Geo-Information, 10(1), 23. https://doi.10.3390/ijgi10010023

Wurm, M., Goebel, J., Wagner, G. G., Weigand, M., Dech, S., \& Taubenböck, H. (2019a). Inferring floor area ratio thresholds for the delineation of city centers based on cognitive perception. Environment and Planning B: Urban Analytics and City Science, 239980831986934. https:// doi.10.1177/2399808319869341

Wurm, M., Stark, T., Zhu, X. X., Weigand, M., \& Taubenböck, H. (2019b). Semantic segmentation of slums in satellite images using transfer learning on fully convolutional neural networks. ISPRS Journal of Photogrammetry and Remote Sensing, 150, 59-69. https://doi.10.1016/j.isprsjprs.2019.02.006

Wurm, M., Taubenböck, H., Krings, S., Birkmann, J., Roth, A., \& Dech, S. (2009). Derivation of population distribution for vulnerability assessment in flood-prone German cities using multisensoral remote sensing data. In U. Michel \& D. L. Civco (Eds.), Remote sensing for environmental monitoring, GIS applications, and geology IX. Bellingham, WA: SPIE. https://doi.10.1117/12.830318

Wurm, M., Taubenböck, H., Schardt, M., Esch, T., \& Dech, S. (2011). Object-based image information fusion using multisensor earth observation data over urban areas. International Journal of Image and Data Fusion, 2(2), 121-147. https://doi.10.1080/19479832.2010.543934

Young, N. E., Anderson, R. S., Chignell, S. M., Vorster, A. G., Lawrence, R., \& Evangelista, P. H. (2017). A survival guide to Landsat preprocessing. Ecology, 98(4), 920-932. https://doi.10.1002/ ecy. 1730

Yuan, J., Chowdhury, P. K. R., McKee, J., Yang, H. L., Weaver, J., \& Bhaduri, B. (2018). Exploiting deep learning and volunteered geographic information for mapping buildings in Kano, Nigeria. Scientific Data, 5(1) 180217. https://doi.10.1038/sdata.2018.217

Zegras, C. (2010). The built environment and motor vehicle ownership and use: Evidence from Santiago de Chile. Urban Studies, 47(8), 1793-1817. https://doi.10.1177/0042098009356125 
Zhang, H., Zhao, F., \& Sutherland, J. W. (2013). Manufacturing scheduling for reduced energy cost in a smart grid scenario. In A. Y. C. Nee, B. Song, \& S.-K. Ong (Eds.), Re-engineering manufacturing for sustainability (pp. 183-190). Berlin: Springer Science \& Business Media.

Zhang, S., Liu, X., Tang, J., Cheng, S., \& Wang, Y. (2019). Urban spatial structure and travel patterns: Analysis of workday and holiday travel using inhomogeneous Poisson point process models. Computers, Environment and Urban Systems, 73, 68-84. https://doi.10.1016/j.compenvurbsys.2018.08.005

Zhang, Y., \& Guindon, B. (2006). Using satellite remote sensing to survey transport-related urban sustainability. International Journal of Applied Earth Observation and Geoinformation, 8(3), 149-164. https://doi.10.1016/j.jag.2005.08.005

Zhang, Y., Guindon, B., \& Sun, K. (2010). Measuring Canadian urban expansion and impacts on work-related travel distance: 1966-2001. Journal of Land Use Science, 5(3), 217-235. https://doi.10 $.1080 / 1747423 x .2010 .500684$

Zhu, X. X., Tuia, D., Mou, L., Xia, G.-S., Zhang, L., Xu, F., \& Fraundorfer, F. (2017). Deep learning in remote sensing: A comprehensive review and list of resources. IEEE Geoscience and Remote Sensing Magazine, 5(4), 8-36. https://doi.10.1109/mgrs.2017.2762307 